OPEN ACCESS

Edited by:

Zhenxiang Cheng,

University of Wollongong, Australia

Reviewed by:

Li Zhu,

Carnegie Institution for Science (CIS),

United States

Hui Li,

Temple University, United States

*Correspondence:

Jingjing Wang

scu_wjj@163.com

Chuanzhao Zhang

zcz19870517@163.com

Specialty section:

This article was submitted to

Theoretical and Computational

Chemistry,

a section of the journal

Frontiers in Chemistry

Received: 05 March 2020

Accepted: 01 April 2020

Published: 28 April 2020

Citation:

Ju M, Wang J, Huang J, Zhang C.

Jin Y, Sun W, Li S and Chen Y (2020)

The Microstructure and Electronic Properties of Yttrium Oxide Doped With Cerium: A Theoretical Insight.

Front. Chem. 8:338

doi: 10.3389/fchem.2020.00338

\section{The Microstructure and Electronic Properties of Yttrium Oxide Doped With Cerium: A Theoretical Insight}

\author{
Meng Ju ${ }^{1,2}$, Jingjing Wang ${ }^{2 *}$, Jing Huang ${ }^{1}$, Chuanzhao Zhang ${ }^{3 *}$, Yuanyuan Jin ${ }^{3}$, \\ Weiguo Sun ${ }^{4}$, Shichang $\mathrm{Li}^{5}$ and Yunhong Chen ${ }^{2}$ \\ ${ }^{1}$ School of Physical Science and Technology, Southwest University, Chongqing, China, ${ }^{2}$ College of Computer and \\ Information Engineering, Hubei Normal University, Huangshi, China, ${ }^{3}$ Department of Physics and Optoelectronic Engineering, \\ Yangtze University, Jingzhou, China, ${ }^{4}$ Centre for Science at Extreme Conditions and School of Physics and Astronomy, \\ Scottish Universities Physics Alliance (SUPA), University of Edinburgh, Edinburgh, United Kingdom, ${ }^{5}$ School of Science, \\ Chongqing University of Posts and Telecommunications, Chongqing, China
}

Trivalent Cerium $\left(\mathrm{Ce}^{3+}\right)$ doped Yttrium Oxide $\left(\mathrm{Y}_{2} \mathrm{O}_{3}\right)$ host crystal has drawn considerable interest due to its popular optical $5 d-4 f$ transition. The outstanding optical properties of $\mathrm{Y}_{2} \mathrm{O}_{3}$ :Ce system have been demonstrated by previous studies but the microstructures still remain unclear. The lacks of $\mathrm{Y}_{2} \mathrm{O}_{3}$ :Ce microstructures could constitute a problem to further exploit its potential applications. In this sense, we have comprehensively investigated the structural evolutions of $\mathrm{Y}_{2} \mathrm{O}_{3}$ :Ce crystals based on the CALYPSO structure search method in conjunction with density functional theory calculations. Our result uncovers a new rhombohedral phase of $\mathrm{Y}_{2} \mathrm{O}_{3}$ :Ce with $\mathrm{R}-3$ group symmetry. In the host crystal, the $\mathrm{Y}^{3+}$ ion at central site can be naturally replaced by the doped $\mathrm{Ce}^{3+}$, resulting in a perfect cage-like configuration. We find an interesting phase transition that the crystallographic symmetry of $\mathrm{Y}_{2} \mathrm{O}_{3}$ changes from cubic to rhombohedral when the impurity $\mathrm{Ce}^{3+}$ is doped into the host crystal. With the nominal concentration of $\mathrm{Ce}^{3+}$ at $3.125 \%$, many metastable structures are also identified due to the different occupying points in the host crystal. The $X$-ray diffraction patterns of $\mathrm{Y}_{2} \mathrm{O}_{3}$ :Ce are simulated and the theoretical result is comparable to experimental data, thus demonstrating the validity of the lowest energy structure. The result of phonon dispersions shows that the ground state structure is dynamically stable. The analysis of electronic properties indicate that the $\mathrm{Y}_{2} \mathrm{O}_{3}$ :Ce possesses a band gap of $4.20 \mathrm{eV}$ which suggests that the incorporation of impurity $\mathrm{Ce}^{3+}$ ion into $\mathrm{Y}_{2} \mathrm{O}_{3}$ host crystal leads to an insulator to semiconductor transition. Meanwhile, the strong covalent bonds of $O$ atoms in the crystal, which may greatly contribute to the stability of ground state structure, are evidenced by electron localization function. These obtained results elucidate the structural and bonding characters of $\mathrm{Y}_{2} \mathrm{O}_{3}$ : $\mathrm{Ce}$ and could also provide useful insights for understanding the experimental phenomena.

Keywords: crystal structure prediction (CSP), electronic propercies, structural evolution, rare earth element, theoretical calculation DFT 


\section{INTRODUCTION}

The rare-earth Cerium ions doped crystals constitute an attractive class of materials that have been extensively used in many kinds of fields including scintillation phosphors, laser medium, and white light emitting diode phosphors (Han et al., 2019; Lin et al., 2019; Masanori et al., 2020). The outstanding optical behaviors of trivalent Cerium ion $\left(\mathrm{Ce}^{3+}\right)$ has drawn considerable interest due to its popular optical 5d-4f transition. Among various host materials, Yttrium Oxide $\left(\mathrm{Y}_{2} \mathrm{O}_{3}\right)$ crystal is considered to be the most promising sesquioxide host because of its unique chemical and thermal stability. The $\mathrm{Y}_{2} \mathrm{O}_{3}$ host crystal is also one of the multifunctional materials that can give rise to many application areas owing to its fabulous capacity of incorporating the activated laser ions (Ming et al., 2018; Wang et al., 2018; Ju et al., 2020). The latest study has indicated that the $\mathrm{Ce}^{3+}$ doped $\mathrm{Y}_{2} \mathrm{O}_{3}$ crystals $\left(\mathrm{Y}_{2} \mathrm{O}_{3}: \mathrm{Ce}\right)$ exhibit dominant emission bands at around $380 \mathrm{~nm}$ and relatively low intensive band at $560 \mathrm{~nm}$ (Gieszczyk et al., 2019). The results further demonstrate the ideal applications of energy storage phosphors for $\mathrm{Y}_{2} \mathrm{O}_{3}$ :Ce. The excellent advantages of $\mathrm{Y}_{2} \mathrm{O}_{3}$ :Ce can also be evidenced by the effective use as various laser ceramics (Lupei et al., 2017).

It is well-known that the laser actions can be generally identified in the absorption and emission spectra of rareearth doped materials. In order to explore the luminescent properties of $\mathrm{Y}_{2} \mathrm{O}_{3}: \mathrm{Ce}$, Jia et al. (2001) had synthesized the $\mathrm{Y}_{2} \mathrm{O}_{3}$ : $\mathrm{Ce}$ nanoparticles in experiments and measured the photoluminescence spectra at room temperature. Their results revealed that the strong emissions cover the ultraviolet band from $240 \mathrm{~nm}$ to $380 \mathrm{~nm}$. To explain the emission lines of the spectra, Loitongbam et al. (2013) measured the luminescence intensities of $\mathrm{Y}_{2} \mathrm{O}_{3}$ :Ce and found that the characteristic blue color emissions at 424 and $486 \mathrm{~nm}$ are originated from $\mathrm{Ce}^{3+}$ ion $5 \mathrm{~d}$ (spectra terms) $\rightarrow$ ff (spectra terms). An unexpected optical activity, including up and down conversions, for $\mathrm{Y}_{2} \mathrm{O}_{3}$ : Ce crystal was firstly observed by Marin et al. (2013). Although the laser actions were established by a few studies, many researchers were motivated to probe the structural properties of $\mathrm{Y}_{2} \mathrm{O}_{3}$ : Ce. The effect of doping $\mathrm{Ce}^{3+}$ ion into $\mathrm{Y}_{2} \mathrm{O}_{3}$ fibers was investigated by Zhu et al. (2008). They found that the obvious quenching of the luminescence occurred at $\mathrm{Ce}^{3+}$ concentration of $5 \%$. By using the solid-state-reactive method, Liu et al. (2020) carried out a study on the structures of a series of $\mathrm{Ce}^{3+}$ doped $\mathrm{Y}_{2} \mathrm{O}_{3}$ ternary ceramics. The results demonstrated that the solubility of $\mathrm{Ce}^{3+}$ concentration at $4 \%$ could broaden emission spectra and lead to a large red-shift, which is attractive for the white light emitting. A recent research on the structural properties of $\mathrm{Y}_{2} \mathrm{O}_{3}$ : Ce was conducted by Krutikova et al. (2020). The nanopowders were obtained by laser ablation and the X-ray diffraction (XRD) patterns of $\mathrm{Y}_{2} \mathrm{O}_{3}$ : $\mathrm{Ce}$ crystal were reported. By looking at the investigations concerning $\mathrm{Y}_{2} \mathrm{O}_{3}$ :Ce in the literatures, it can be concluded that the systematic electronic structures have not yet been explored, especially for the theoretical insights. Furthermore, the lacks of $\mathrm{Y}_{2} \mathrm{O}_{3}$ :Ce microstructures constitute a problem to exploit its potential prospects in many applications.

In this paper, we have performed a systematic study on the stable structures and electronic properties for $\mathrm{Y}_{2} \mathrm{O}_{3}$ doped with $\mathrm{Ce}^{3+}$ system. By using the CALYPSO (Crystal structure AnaLYsis by Particle Swarm Optimization) structure search method (Wang et al., 2010, 2012; Li et al., 2014) combined with first-principle calculation, the low-lying energy structures of $\mathrm{Y}_{2} \mathrm{O}_{3}$ : $\mathrm{Ce}$ are extensively searched. A large number of candidate structures are obtained and the ground state structure together with the first four metastable structures is analyzed in detail. Based on the obtained lowest energy structure of $\mathrm{Y}_{2} \mathrm{O}_{3}$ :Ce, we thoroughly conduct a calculation of the electronic properties, which could provide powerful guidance for further experimental and theoretical studies.

\section{COMPUTATIONAL DETAILS}

We have carried out an unbiased structure search for $\mathrm{Y}_{2} \mathrm{O}_{3}$ doped with $\mathrm{Ce}^{3+}$ system based on the CALYPSO method (Wang et al., 2010, 2012; Li et al., 2014). The CALYPSO is able to successfully predict the stable structures only with given chemical composition of the system ( $\mathrm{Lu}$ et al., 2013, 2017, 2018; Lu and Chen, 2018). The detailed method of CALYPSO has been reported in many papers (Ju et al., 2016, 2017, 2019a,b). In this work, the structure searches are performed for $\mathrm{Y}_{2} \mathrm{O}_{3}$ doped with $\mathrm{Ce}$ system at 80 atoms in one unit cell. The obtained lowlying energy structures are used to perform further geometric optimizations. We conduct the $a b$ initio structural relaxations and electronic properties calculations in the framework of density functional theory (DFT) by using the local density approximation (LDA) exchange correlation functional, as implemented in the Vienna Ab Initio Simulation Package (VASP) (Kresse and Hafner, 1993; Kresse and Furthmuller, 1996; Perdew et al., 1996). Considering the strong f-electrons correlations within the heavy $\mathrm{Ce}^{3+}$ ion, an onsite Coulomb repulsion $U=5.0 \mathrm{eV}$ is employed in the calculations (Herbst and Waston, 1978). We use the projector-augmented wave method to simulate the valence electron space of $\mathrm{Ce}, \mathrm{Y}$, and $\mathrm{O}$ atoms. The used electrons are $4 f^{1} 5 s^{2} 5 p^{6} 5 d^{1} 6 s^{2}, 4 s^{2} 4 p^{6} 4 d^{1} 5 s^{2}$, and $2 s^{2} 2 p^{4}$, respectively. Sufficiently fine Monkhorst-Pack $\mathrm{k}$ meshes and $500 \mathrm{eV}$ cutoff energy have been chosen to make sure that the calculated enthalpy of each atom is $<1 \mathrm{meV}$. By using a super cell approach, the phonon dispersion spectra are calculated in PHONOPY code (Atsushi et al., 1993). The electron localization function (ELF) (Becke and Edgecombe, 1990; Savin et al., 1992) analysis of $\mathrm{Y}_{2} \mathrm{O}_{3}$ : $\mathrm{Ce}$ is performed and the results are depicted in the VESTA software (Momma and Izumi, 2011). The projected Crystal Orbital Hamilton Population (COHP) (Richard and Peter, 1993) are calculated by the LOBSTER code (Volker et al., 2011; Stefan et al., 2016).

\section{RESULTS AND DISCUSSIONS Crystal Structures}

The stable structures for $\mathrm{Y}_{2} \mathrm{O}_{3}$ :Ce system are favorably identified by using the method described in section Computational Details. On the basis of total energies from low to high, we have plotted the lowest-energy structure of $\mathrm{Y}_{2} \mathrm{O}_{3}$ : Ce in Figure 1, together with the local $\left[\mathrm{CeO}_{6}\right]^{9-}$ complex ligand. Noticeably, the ground 


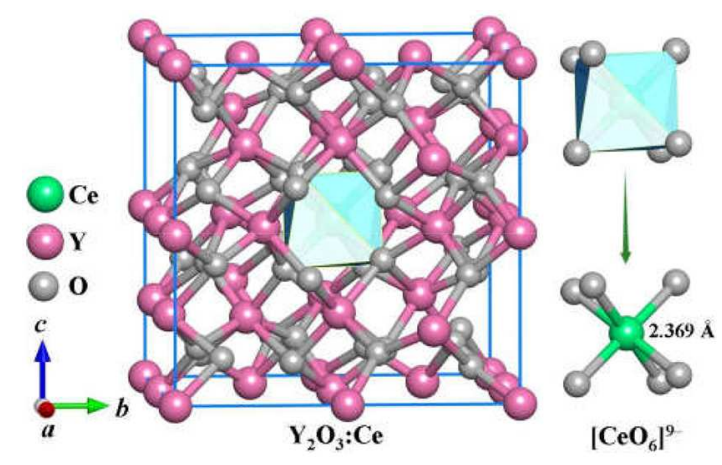

FIGURE 1 | The ground state structure of $\mathrm{Y}_{2} \mathrm{O}_{3}: \mathrm{Ce}$.
TABLE 1 | Coordinates of all atoms for the ground state $\mathrm{Y}_{2} \mathrm{O}_{3}$ :Ce.

\begin{tabular}{lcccc}
\hline Atom & $\boldsymbol{x}$ & $\boldsymbol{y}$ & $\boldsymbol{z}$ & Wyckoff site symmetry \\
\hline Ce & 0.50000 & 0.50000 & 0.50000 & $1 \mathrm{~b}$ \\
Y1 & 0.50000 & 0 & 0 & $3 \mathrm{~d}$ \\
Y4 & 0 & 0.50000 & 0.50000 & $3 \mathrm{e}$ \\
Y5 & 0 & 0 & 0 & $1 \mathrm{a}$ \\
Y8 & 1.21723 & -0.00048 & -0.24957 & $6 f$ \\
Y9 & 0.78317 & -0.50109 & -0.24904 & $6 f$ \\
Y10 & 0.28219 & 0.00104 & 0.25009 & $6 f$ \\
Y11 & 0.72090 & -0.50141 & 0.24728 & $6 f$ \\
O1 & 0.64138 & -0.12945 & -0.09800 & $6 f$ \\
O2 & 1.14358 & -0.62871 & 0.40217 & $6 f$ \\
O3 & 0.35267 & -0.63253 & 0.60591 & $6 f$ \\
O4 & 0.85797 & -0.12919 & 0.09753 & $6 f$ \\
O5 & 0.85966 & 0.12874 & 0.40167 & $6 f$ \\
O6 & 0.35814 & -0.37026 & -0.09599 & $6 f$ \\
O7 & 1.14102 & -0.37007 & 0.09751 & $6 f$ \\
O8 & 0.64188 & 0.12739 & 0.59868 & 6f \\
\hline
\end{tabular}

05) position. For the configuration of isomer (d), it is seen that the $\mathrm{Ce}^{3+}$ ions appear at the center sites of bottom and top in the crystal lattice. The isomer (d) is assigned to P1 group symmetry and is $0.27 \mathrm{eV}$ energetically higher than ground state structure.

Although the X-ray powder diffraction (XRD) patterns of $\mathrm{Y}_{2} \mathrm{O}_{3}$ :Ce crystals have been extensively studied, there appears to be inconsistencies of the spectra (Chien and Yu, 2008; Taibeche et al., 2016; Kumar et al., 2017). In order to clarify the crystal characters of the lowest-energy structure, we simulate the XRD patterns of $\mathrm{Y}_{2} \mathrm{O}_{3}: \mathrm{Ce}$ in the $2 \theta$ range of $15-65^{\circ}$. The result compared with experimental data is presented in Figure 3. It is evident that the calculated spectrum is in perfect agreement with the values measured by Kumar et al. (2017), demonstrating the validity of the lowest energy structure as well as the accuracy of our theoretical calculations. It should be pointed out that the simulated diffraction peak at $34^{\circ}$ is ascribed to the (400) plane direction. This is accord with the result obtained by Taibeche et al. (2016) but different from the measured value proposed by Chien and $\mathrm{Yu}$ (2008). For comparison, the XRD patterns of the four isomers (a), (b), (c), and (d) are also provided in Figure 3. Although the overall distribution of the peaks in isomers is closely similar with each other, there are minor differences in the relative intensities. To evaluate the dynamical stability of $\mathrm{Y}_{2} \mathrm{O}_{3}$ :Ce, the phonon spectrum within the Brillouin zone of ground state structure are calculated. Figure 4 illustrates the phonon dispersion curves along the high-symmetry directions including $\mathrm{F}, \Gamma$, and $\mathrm{Z}$. Clearly, the overall values in Figure 4 are positive and no virtual frequencies are observed in the full Brillouin zone. It is concluded that the rhombohedral phase structure of $\mathrm{Y}_{2} \mathrm{O}_{3}$ :Ce crystal is dynamically stable.

\section{Electronic Properties}

To further elucidate the electronic properties of $\mathrm{Y}_{2} \mathrm{O}_{3}$ : Ce crystal, we have performed a series of $a b$ initio calculations including the 

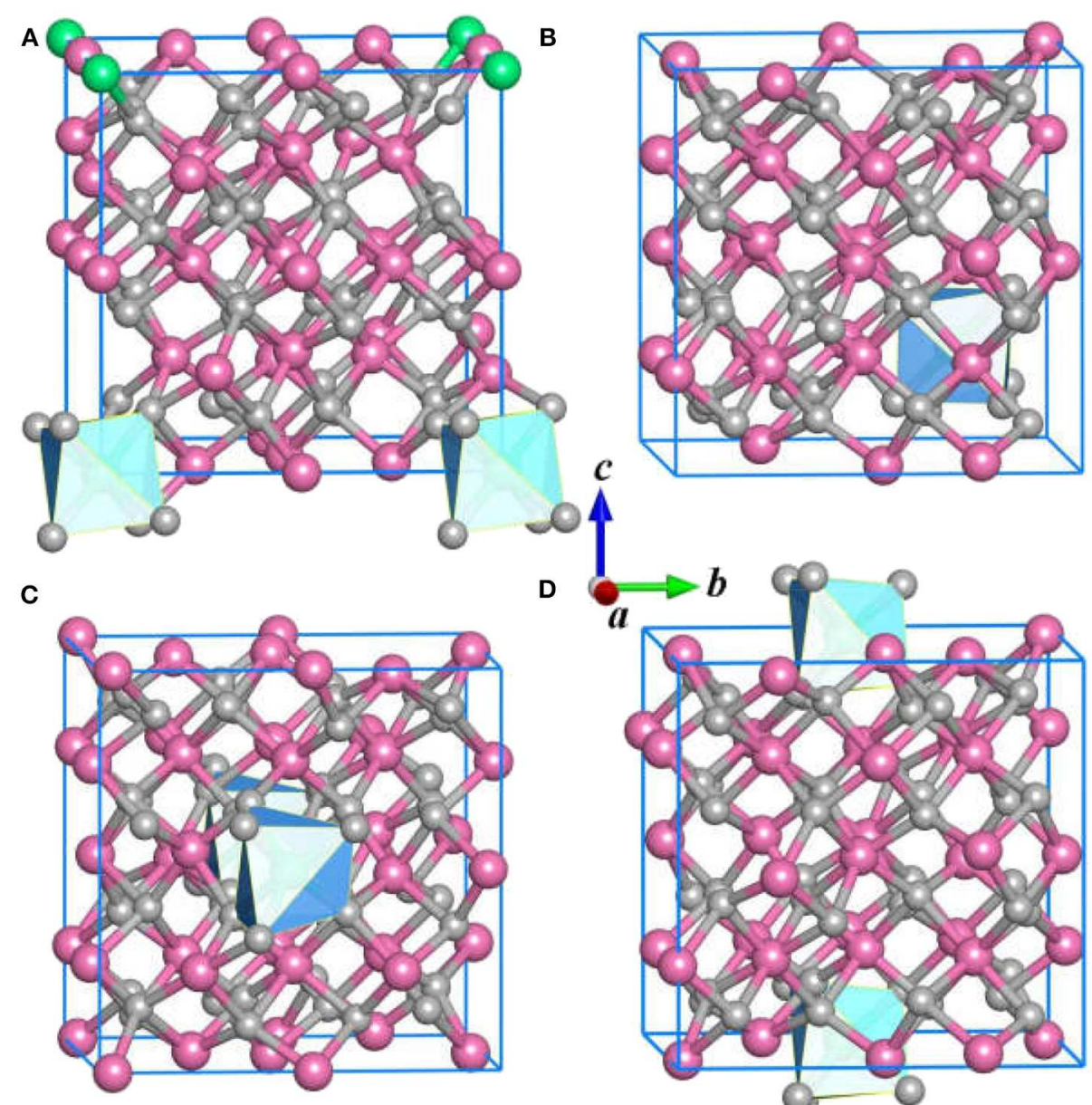

D
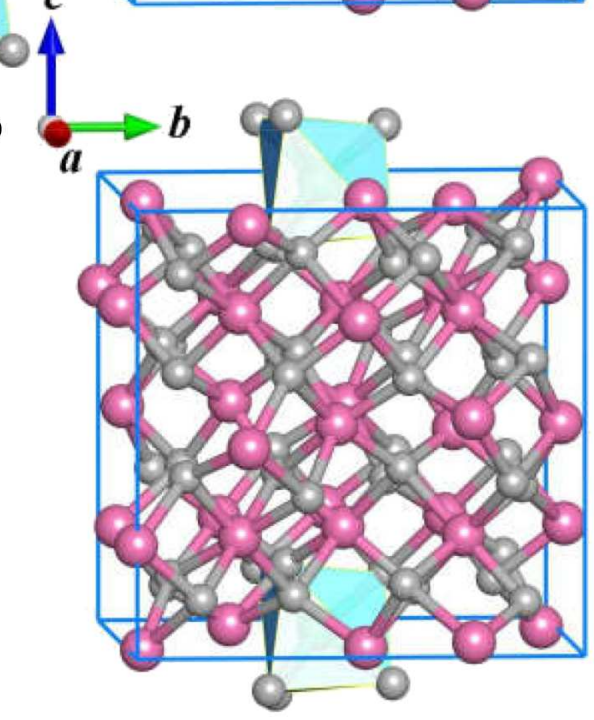

FIGURE 2 | The (A-D) isomers for $\mathrm{Y}_{2} \mathrm{O}_{3}$ :Ce.

electronic band structures, total and partial electronic density of states and electron localization functions. The calculated band structure and density of states (DOS) are plotted together in Figure 5. Our calculated results show that both of the conduction band minimum and valence band maximum are identified at $\Gamma$ site. The band structure is considered to be a typical of semiconductor with relatively flat top of the valence bands. According to the calculations, the band gap value of ground state $\mathrm{Y}_{2} \mathrm{O}_{3}$ :Ce is equal to $4.20 \mathrm{eV}$ directly at $\Gamma$ point. This result is very close to the energy gap of $\mathrm{Y}_{2} \mathrm{O}_{3}: \mathrm{Nd}$ system (Ju et al., 2020) but significantly smaller than that of pure $\mathrm{Y}_{2} \mathrm{O}_{3}$ crystal (Wilk and Wallace, 2002). The direct band gap of $4.20 \mathrm{eV}$ suggests a semiconductor character of the $\mathrm{Y}_{2} \mathrm{O}_{3}$ :Ce. In addition to the electronic band gap, the electronic calculations of high-symmetry directions are in accordance with the above analysis based on phonon spectrum. In Figure 5A, we can clearly see that the band structures can be divided into three parts. The high conduction band is above $4.20 \mathrm{eV}$ while the low valence band is below $-0.17 \mathrm{eV}$. Interestingly, an extremely narrow valence band is observed just below the Fermi level. This result is greatly different with the band structures of pure $\mathrm{Y}_{2} \mathrm{O}_{3}$. The calculations show that the narrow valence band is caused by the electronic Alpha states. In contrast, the Beta electrons are not identified near the Fermi level. In order to explore the origins of the electronic bands, we further calculate the partial DOS including s, p, d and $f$ states. The calculated DOS are depicted in Figure 5B. It can be clearly seen that the high conduction bands are mainly formed by $\mathrm{d}$ and $\mathrm{p}$ states. The $\mathrm{p}$ electrons are calculated to be the strongest state in the low valence bands. Moreover, the partial DOS of $\mathrm{Y}_{2} \mathrm{O}_{3}$ :Ce reveals that the extremely narrow valence band near Fermi level is ascribed to the f orbital, which suggests that the impurity $\mathrm{Ce}^{3+}$ ion leads to a dramatic reduction of the band gap. In other words, it is concluded that the incorporation of the doped $\mathrm{Ce}^{3+}$ ion into $\mathrm{Y}_{2} \mathrm{O}_{3}$ host crystal results in an insulator to semiconductor transition.

To achieve foundational understanding of the bonding character and distribution of electrons of $\mathrm{Y}_{2} \mathrm{O}_{3}$ : $\mathrm{Ce}$ crystal, we have carried out a calculation on the electron localization functions based on the ground state structure. The visually ELF of the structure and (100) plane are presented together in Figure 6. Obviously, the electrons near the cationic atoms are greatly localized with ELF values at $\sim 0.9$ while the ELF values 


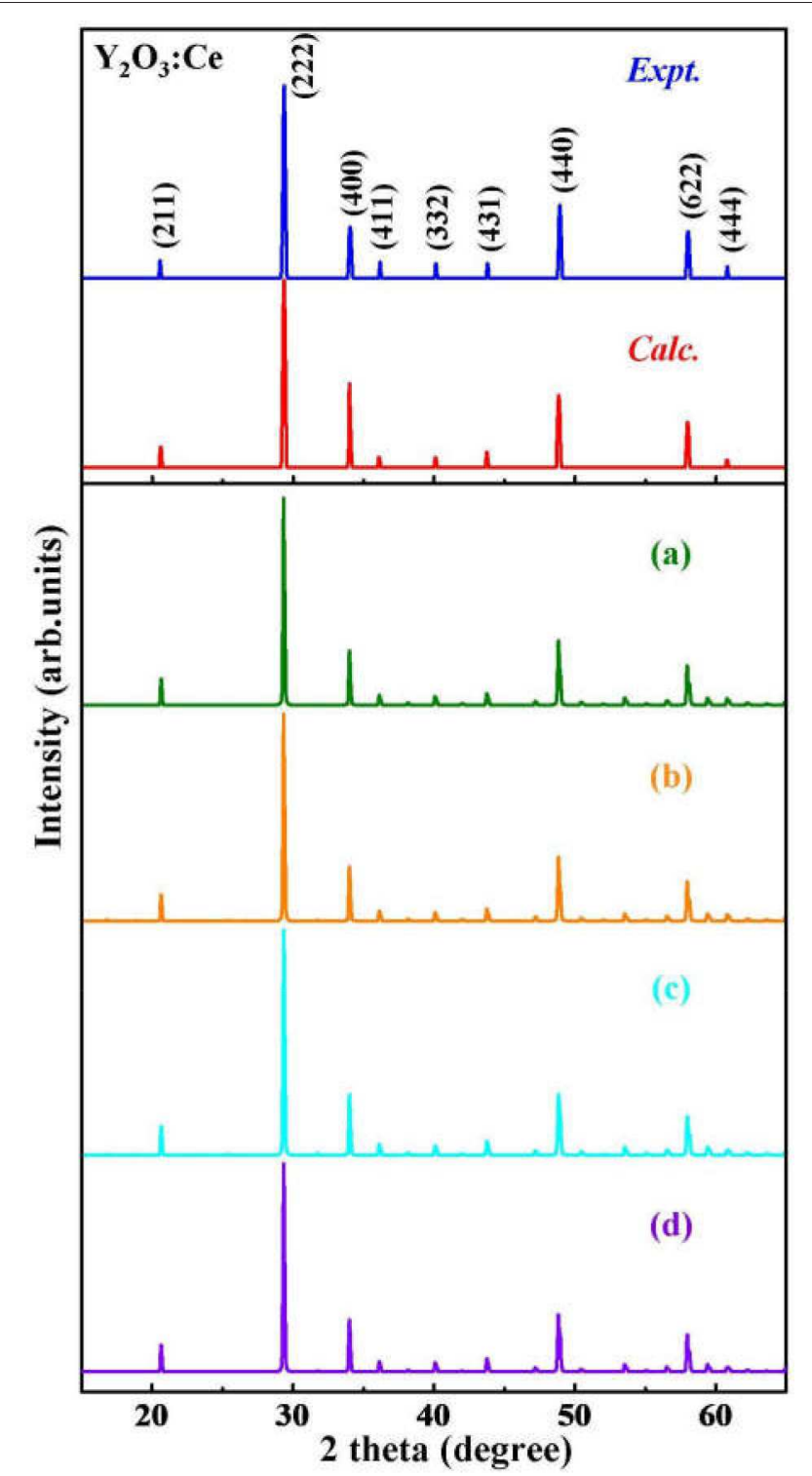

FIGURE 3 | The simulated XRD patterns for ground state $\mathrm{Y}_{2} \mathrm{O}_{3}$ :Ce and isomers $(\mathbf{a}-\mathbf{d})$, compared with measured spectra.

in the crystal lattice are nearly zero. This result indicates that the electrons localization on $\mathrm{Ce}$ and $\mathrm{Y}$ atoms broadens toward $\mathrm{O}$ atoms, forming a complete charge delocalization in the vicinity of $\mathrm{O}$ atoms. The strong ionic bonds are identified between $\mathrm{Ce}$ $\mathrm{O}$ and Y-O. Furthermore, our calculations also show that the value of ELF at Ce atom is relatively larger than the ELF of Y atoms. This phenomenon can be explained as the remaining $4 \mathrm{f}$ (Masanori et al., 2020) electron of $\mathrm{Ce}^{3+}$ ion. It should be pointed out that there are strong charge localizations between $\mathrm{O}-\mathrm{O}$ atoms, demonstrating the covalent bond of $\mathrm{O}$ atoms. To further quantitatively estimate the contribution of bonds between $\mathrm{O}$ atoms, we have presented the projected Crystal Orbital Hamilton

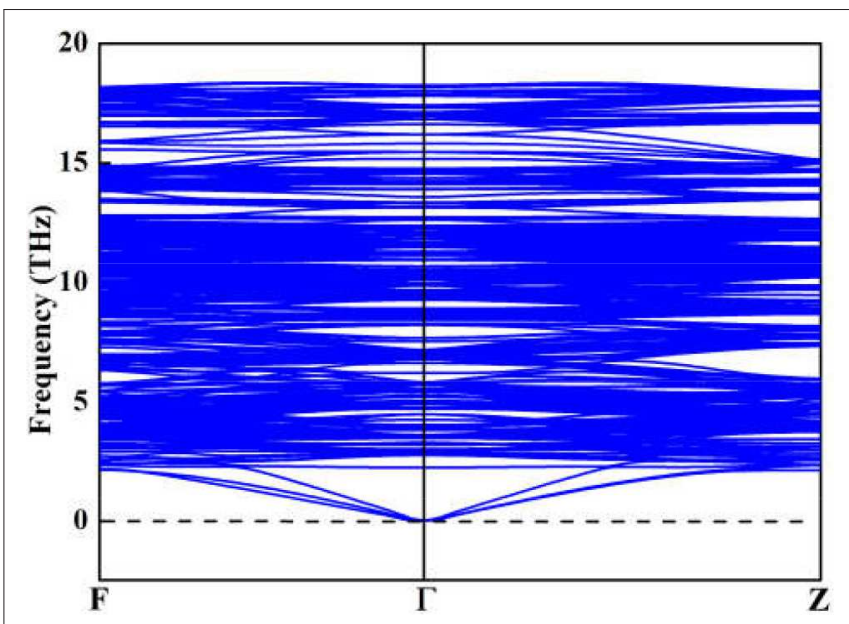

FIGURE 4 | Simulated phonon dispersions of the lowest energy structure for $\mathrm{Y}_{2} \mathrm{O}_{3}: \mathrm{Ce}$.
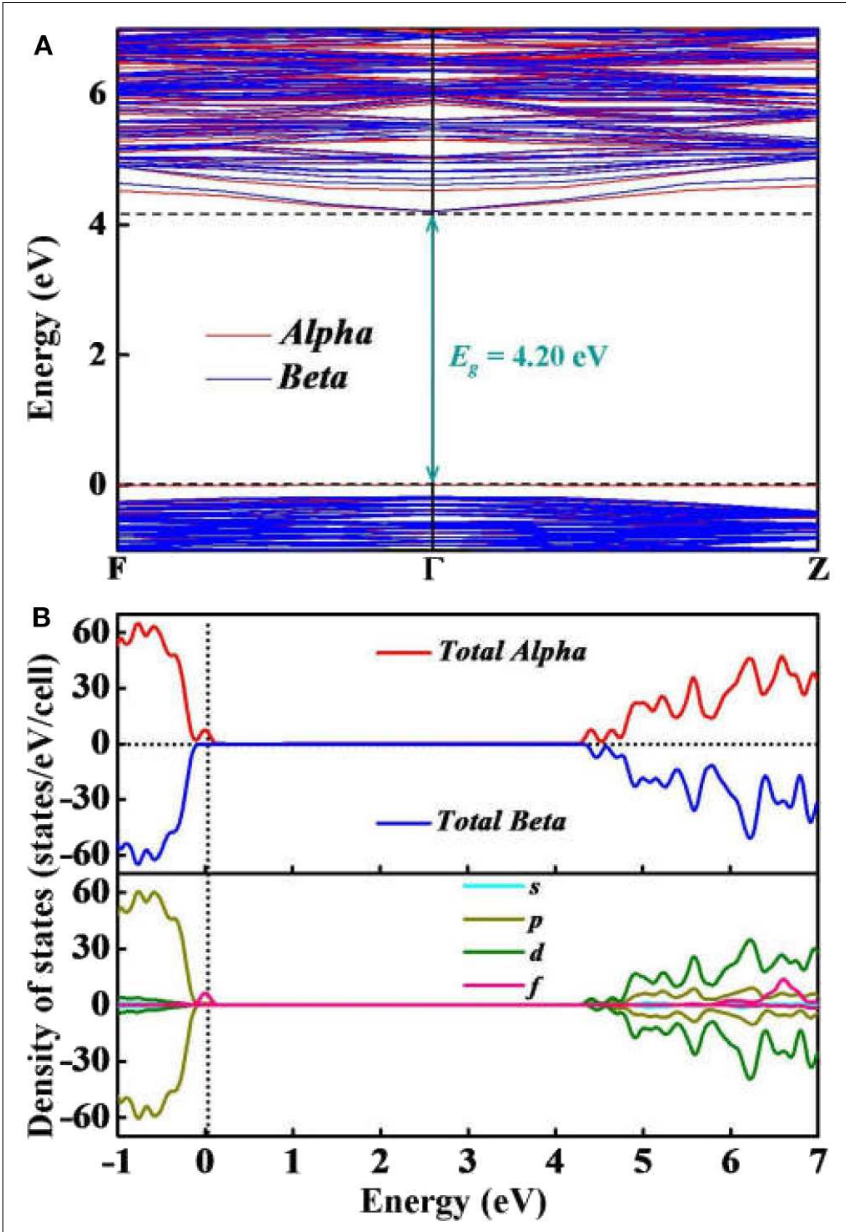

FIGURE 5 | Simulated (A) electronic bands and (B) total and partial DOS of $\mathrm{Y}_{2} \mathrm{O}_{3}$ : $\mathrm{Ce}$. 

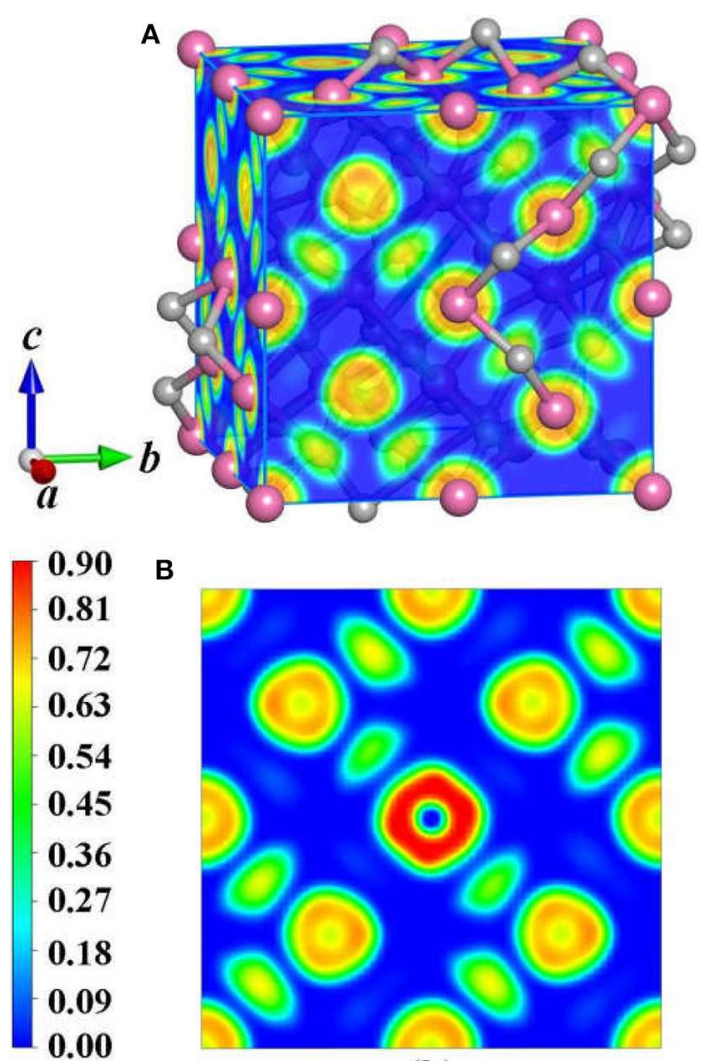

FIGURE 6 | ELF of the $(\mathbf{A})$ structure and $(\mathbf{B})<100>$ plane for $\mathrm{Y}_{2} \mathrm{O}_{3}$ :Ce.

Population (-pCOHP) curves for the O-O bonds in $\mathrm{Y}_{2} \mathrm{O}_{3}$ :Ce. As shown in Figure 7, the strong bonding contributions of $\mathrm{O}$ $\mathrm{O}$ bonds are evidenced. The bond features near the Fermi level can be ascribed to covalent. It is convinced that the excellent stability of $\mathrm{Y}_{2} \mathrm{O}_{3}$ :Ce crystal is owing to the strong covalent bonds of $\mathrm{O}$ atoms.

\section{CONCLUSION}

To summarize, we have systematically reported the structural evolutions, doping site locations and electronic properties of $\mathrm{Y}_{2} \mathrm{O}_{3}$ crystal doped with $\mathrm{Ce}^{3+}$ ions. By using the CALYPSO method in conjunction with first-principles calculations, a novel stable phase with R-3 space group is identified for the first time. For the ground state structure, the doped $\mathrm{Ce}^{3+}$ can naturally occupy the central $\mathrm{Y}^{3+}$ site in the crystal lattice of $\mathrm{Y}_{2} \mathrm{O}_{3}$, forming a standard cage-like structure. The cationic site symmetry of $\mathrm{Ce}^{3+}$ is calculated to be $\mathrm{C}_{3 \mathrm{i}}$ with six equal Ce$\mathrm{O}$ bonds. The first four candidate isomers present different doping sites for $\mathrm{Ce}^{3+}$, which is helpful to investigate the structural evolution of $\mathrm{Y}_{2} \mathrm{O}_{3}$ :Ce. By comparing the simulated XRD patterns with experimental data, we demonstrate the validity of the lowest energy structure. The dynamically stability of $\mathrm{Y}_{2} \mathrm{O}_{3}$ :Ce crystal is carefully examined through the calculation of phonon dispersions. Our results of electronic band structures

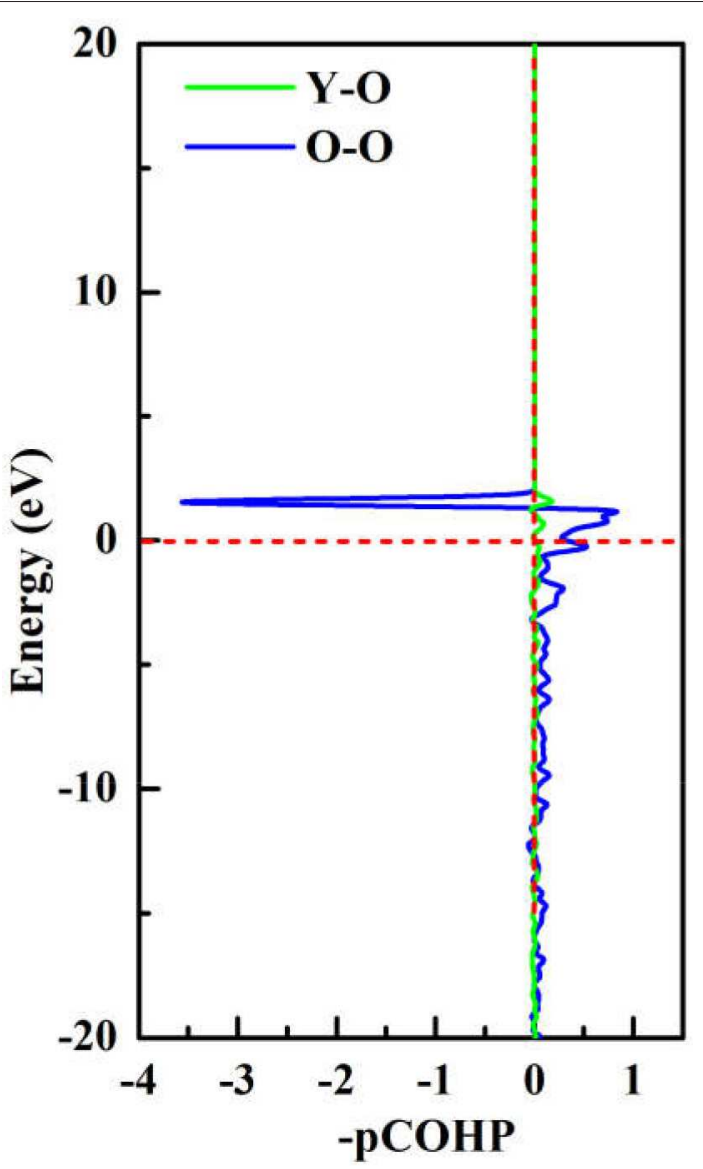

FIGURE 7 | The projected Crystal Orbital Hamilton Population (-pCOHP) curves for the $\mathrm{O}-\mathrm{O}$ bonds in $\mathrm{Y}_{2} \mathrm{O}_{3}$ : $\mathrm{Ce}$.

reveal that both of the conduction band minimum and valence band maximum are located at $\Gamma$ site, leading to a band gap value of $4.20 \mathrm{eV}$. This band gap suggests a semiconductor character of $\mathrm{Y}_{2} \mathrm{O}_{3}$ :Ce system. Interestingly, an extremely narrow valence band near Fermi level is observed in the band structure and the contribution of this band is assigned to $\mathrm{f}$ orbital. In addition, the calculated results of visually ELF show that the charge localizations between $\mathrm{O}-\mathrm{O}$ atoms are dramatically strong, suggesting the covalent bond character of $\mathrm{O}$ atoms in the $\mathrm{Y}_{2} \mathrm{O}_{3}$ : Ce crystal. These findings could provide important information of the microstructures of rare-earth doped laser materials.

\section{DATA AVAILABILITY STATEMENT}

All datasets generated for this study are included in the article/supplementary material.

\section{AUTHOR CONTRIBUTIONS}

MJ, JW, and CZ conceived the idea. MJ, JH, YJ, $\mathrm{YC}$, WS, and SL performed the calculations. MJ, JH, 
and WS wrote the manuscript. All authors reviewed the manuscript.

\section{FUNDING}

This work was financial supported in part by National Natural Science Foundation of China (Nos. 11904297, 11747139,

\section{REFERENCES}

Atsushi, T., Fumiyasu, O., and Isao, T. (1993). First-principles calculations of the ferroelastic transition between rutile-type and $\mathrm{CaCl}_{2}$-type $\mathrm{SiO}_{2}$ at high pressures. Phys. Rev. B 78:134106.

Becke, A. D., and Edgecombe, K. E. (1990). A simple measure of electron localization in atomic and molecular systems. J. Chem. Phys. 92, 5397-5403. doi: $10.1063 / 1.458517$

Chien, W. C., and Yu, Y. Y. (2008). Preparation of $\mathrm{Y}_{2} \mathrm{O}_{3}: \mathrm{Ce}^{3+}$ phosphors by homogeneous precipitation inside bicontinuous cubic phase. Mater. Lett. 62, 4217-4219. doi: 10.1016/j.matlet.2008.06.041

Gieszczyk, W., Bilski, P., Kłosowski, M., Mrozik, A., Zorenko, Yu., Zorenko, T., et al. (2019). Luminescent properties of undoped and $\mathrm{Ce}^{3+}$ doped crystals in $\mathrm{Y}_{2} \mathrm{O}_{3}-\mathrm{Lu}_{2} \mathrm{O}_{3}-\mathrm{Al}_{2} \mathrm{O}_{3}$ triple oxide system grown by micro-pulling-down method. Opt. Mater. 89, 408-413. doi: 10.1016/j.optmat.2019.01.023

Han, Z. K., Zhang, L., Liu, M., Maria, V. G. P., and Gao, Y. (2019). The structure of oxygen vacancies in the near-surface of reduced $\mathrm{CeO}_{2}$ (111) under strain. Front. Chem. 7:436. doi: 10.3389/fchem.2019.00795

Herbst, J. F., and Waston, R. E. (1978). Relativistic calculations of 4f excitation energies in the rare-earth metals: further results. Phys. Rev. B 17, 3089-3098. doi: 10.1103/PhysRevB.17.3089

Jia, W., Wang, Y., Fernandez, F., Wang, X., Huang, S., and Yen, W. M. (2001). Photoluminescence of $\mathrm{Ce}^{3+}, \mathrm{Tb}^{3+}: \mathrm{Y}_{2} \mathrm{O}_{3}$ nanoclusters embedded in $\mathrm{SiO}_{2}$ sol-gel glasses. Mater. Sci. Eng. C 16, 55-58. doi: 10.1016/S0928-4931(01)00298-3

Ju, M., Lu, C., Yeung, Y., Kuang, X., Wang, J., and Zhu, Y. (2016). Structural evolutions and crystal field characterizations of Tm-doped $\mathrm{YAlO}_{3}$ : new theoretical insights. ACS Appl. Mater. Interfaces 8, 30422-30429. doi: 10.1021/acsami.6b09079

Ju, M., Sun, G., Kuang, X., Lu, C., Zhu, Y., and Yeung, Y. (2017). Theoretical investigation of the electronic structure and luminescence properties for $\mathrm{NdxY} 1-\mathrm{xAl}_{3}\left(\mathrm{BO}_{3}\right) 4$ non-linear laser crystal. J. Mater. Chem. C 5, 7174-7181. doi: 10.1039/C7TC01911D

Ju, M., Xiao, Y., Sun, W., Lu, C., and Yeung, Y. (2020). In-depth determination of the microstructure and energy transition mechanism for $\mathrm{Nd}^{3+}$. doped yttrium oxide laser crystals. J. Phys. Chem. C 124, 2113-2119. doi: 10.1021/acs.jpcc.9b10482

Ju, M., Xiao, Y., Zhong, M., Sun, W., Xia, X., Yeung, Y., et al. (2019b). New theoretical insights into the crystal-field splitting and transition mechanism for $\mathrm{Nd}^{3+}$-doped $\mathrm{Y}_{3} \mathrm{Al}_{5} \mathrm{O}_{12}$. ACS Appl. Mater. Interfaces 11, 10745-10750. doi: 10.1021/acsami.9b00973

Ju, M., Zhong, M., Lu, C., and Yeung, Y. (2019a). Deciphering the microstructure and energy-level splitting of $\mathrm{Tm}^{3+}$-doped yttrium aluminum garnet. Inorg. Chem. 58, 1058-1066. doi: 10.1021/acs.inorgchem.8b 02009

Kresse, G., and Furthmuller, J. (1996). Efficient iterative schemes for ab initio totalenergy calculations using a plane-wave basis set. Phys. Rev. B 54, 11169-11186. doi: 10.1103/PhysRevB.54.11169

Kresse, G., and Hafner, J. (1993). Ab initio molecular dynamics for liquid metals. Phys. Rev. B 47, 558-561. doi: 10.1103/PhysRevB.47.558

Krutikova, I., Ivanov, M., Murzakaev, A., and Nefedova, K. (2020). Lasersynthesized $\mathrm{Ce}^{3+}$ and $\mathrm{Pr}^{3+}$ doped $\mathrm{Y}_{2} \mathrm{O}_{3}$ nanoparticles and their characteristics. Mater. Lett. 265:127435. doi: 10.1016/j.matlet.2020.127435

Kumar, P., Nagpal, K., and Gupta, B. K. (2017). Unclonable security codes designed from multicolour luminescent lanthanide doped $\mathrm{Y}_{2} \mathrm{O}_{3}$ nanorods for anti-counterfeiting. ACS Appl. Mater. Interfaces 9, 14301-14308. doi: 10.1021/acsami.7b03353 and 11804031) and the Fundamental Research Funds for the Central Universities (SWU118055), the Scientific Research Project of Education Department of Hubei Province (No. Q20191301), the Open Research Projects of Wuhan Huada (No. NERCEL-OP2015001) and the Provincial Teaching Research Project in Hubei province of China (Grant No. 2017369).
Li, L., Hao, J., Liu, H., Li, Y., and Ma, Y. (2014). The metallization and superconductivity of dense hydrogen sulfide. J. Chem. Phys. 140:174712. doi: $10.1063 / 1.4874158$

Lin, Y. C., Bettinelli, M., and Karlsson, M. (2019). Unraveling the mechanisms of thermal quenching of luminescence in $\mathrm{Ce}^{3+-}$ doped garnet phosphors. Chem. Mater. 31, 3851-3862. doi: 10.1021/acs.chemmater.8b05300

Liu, Y., Hu, S., Zhang, Y., Wang, Z., Zhou, G., and Wang, S. (2020). Crystal structure evolution and luminescence property of $\mathrm{Ce}^{3+}$-doped $\mathrm{Y}_{2} \mathrm{O}_{3}-\mathrm{Al}_{2} \mathrm{O}_{3}-\mathrm{Sc}_{2} \mathrm{O}_{3}$ ternary ceramics. J. Eur. Ceram. Soc. 40, 840-846. doi: 10.1016/j.jeurceramsoc.2019.10.022

Loitongbam, R. S., Singh, W. R., Phaomei, G., and Singh, N. S. (2013). Blue and green emission from $\mathrm{Ce}^{3+}$ and $\mathrm{Tb}^{3+}$ co-doped $\mathrm{Y}_{2} \mathrm{O}_{3}$ nanoparticles. J. Lumin. 140, 95-102. doi: 10.1016/j.jlumin.2013.02.049

Lu, C., Amsler, M., and Chen, C. (2018). Unraveling the structure and bonding evolution of the newly discovered iron oxide $\mathrm{FeO}_{2}$. Phys. Rev. B 98:054102. doi: 10.1103/PhysRevB.98.054102

Lu, C., and Chen, C. (2018). High-Pressure evolution of crystal bonding structures and properties of FeOOH. J. Phys. Chem. Lett. 9, 2181-2185. doi: 10.1021/acs.jpclett.8b00947

Lu, C., Li, Q., Ma, Y., and Chen, C. (2017). Extraordinary indentation strain stiffening produces superhard tungsten nitrides. Phys. Rev. Lett. 119:11550. doi: 10.1103/PhysRevLett.119.115503

Lu, C., Miao, M., and Ma, Y. (2013). Structural evolution of carbon dioxide under high pressure. J. Am. Chem. Soc. 135, 14167-14171. doi: 10.1021/ja404854x

Lupei, A., Lupei, V., and Hau, S. (2017). Vibronics in optical spectra of $\mathrm{Yb}^{3+}$ and $\mathrm{Ce}^{3+}$ in YAG and $\mathrm{Y}_{2} \mathrm{O}_{3}$ ceramics. Opt. Mater. 63, 143-152. doi: 10.1016/j.optmat.2016.06.024

Marin, R., Back, M., Mazzucco, N., Enrichi, F., Frattini, R., Benedetti, A., et al. (2013). Unexpected optical activity of cerium in $\mathrm{Y}_{2} \mathrm{O}_{3}: \mathrm{Ce}^{3+}, \mathrm{Yb}^{3+}$, $\mathrm{Er}^{3+}$ up and down-conversion system. Dalton Trans. 42, 16837-16845. doi: 10.1039/C3DT51297E

Masanori, N., Akira, M., Daisuke, U., Yuki, M., Yosuke, G., Yoshikazu, M., et al. (2020). Flux growth and superconducting properties of (Ce,Pr) $\mathrm{OBiS}_{2}$ single crystals. Front. Chem. 8:44. doi: 10.3389/fchem.2020.00044

Ming, C., Pei, M., Ren, X., Xie, N., Cai, Y., Qin, Y., et al. (2018). Improving luminescent penetrability by $\mathrm{Tm}^{3+} / \mathrm{Ce}^{3+}$ doped $\mathrm{Y}_{2} \mathrm{O}_{3}$ nanocrystals for optical imaging. Mater. Lett. 218, 154-156. doi: 10.1016/j.matlet.2018.01.169

Momma, K., and Izumi, F. (2011). VESTA 3 for three-dimensional visualization of crystal, volumetric and morphology data. J. Appl. Crystallogr. 44, 1272-1276. doi: $10.1107 /$ S0021889811038970

Perdew, J. P., Burke, K., and Ernzerhof, M. (1996). Generalized gradient approximation made simple. Phys. Rev. Lett. 77, 3865-3868. doi: 10.1103/PhysRevLett.77.3865

Richard, D., and Peter, E. B. (1993). Crystal Orbital Hamilton Populations (COHP). Energy-resolved visualization of chemical bonding in solids based on density-functional calculations. J. Phys. Chem. 97, 8617-8624. doi: 10.1021/j100135a014

Savin, A., Jepsen, O., Flad, J., Andersen, O. K., Preuss, H., and von Schnering, H. G. (1992). Electron localization in solid-state structures of the elements: the diamond structure. Angew. Chem. Int. Ed. Engl. 31, 187-188. doi: 10.1002/anie.199201871

Stefan, M., Volker, L. D., Andrei, L. T., and Richard, D. (2016). LOBSTER: a tool to extract chemical bonding from plane-wave based DFT. J. Comput. Chem. 37, 1030-1035. doi: 10.1002/jcc. 24300

Taibeche, M., Guerbous, L., Boukerika, A., Kechouane, M., Nedjar, R., and Zergoug, T. (2016). Ab-initio simulations at the atomic scale of an exceptional 
experimental photoluminescence signal observed in $\mathrm{Ce}^{3+}$ - doped $\mathrm{Y}_{2} \mathrm{O}_{3}$ sesquioxide system. Opt. 127, 10561-10568. doi: 10.1016/j.ijleo.2016.08.092

Volker, L. D., Andrei, L. T., and Richard, D. (2011). Crystal Orbital Hamilton Population (COHP) analysis as projected from plane-wave basis sets. J. Phys. Chem. A 115, 5461-5466. doi: 10.1021/jp202489s

Wang, N., He, J., Ye, K., Song, X., and L, T. (2018). Sol-gel synthesis and enhanced $1.54 \mu \mathrm{m}$ emission in $\mathrm{Y}_{2} \mathrm{O}_{3}: \mathrm{Yb}^{3+}, \mathrm{Er}^{3+}$ nanophosphors co-doped with $\mathrm{Ce}^{3+}$ ions. Infrared Phys. Technol. 93, 77-80. doi: 10.1016/j.infrared.2018.07.023

Wang, Y., Lv, J., Zhu, L., and Ma, Y. (2010). Crystal structure prediction via particleswarm optimization. Phys. Rev. B 82:094116. doi: 10.1103/PhysRevB.82.094116

Wang, Y., Lv, J., Zhu, L., and Ma, Y. (2012). CALYPSO: a method for crystal structure prediction. Comput. Phys. Commun. 183, 2063-2070. doi: $10.1016 /$ j.cpc.2012.05.008

Wilk, G., and Wallace, R. M. (2002). Alternative gate dielectrics for microelectronics. Mater. Res. Soc. Bull. 27:3. doi: 10.1557/mrs2002.70
Zhu, L., Wang, X., Yu, G., Hou, X., Zhang, G., Sun, J., et al. (2008). Effect of $\mathrm{Ce}^{3+}$ doping and calcination on the photoluminescence of $\mathrm{ZrO}_{2}(3 \%$ $\mathrm{Y}_{2} \mathrm{O}_{3}$ ) fibers. Mater. Res. Bull. 43, 1032-1037. doi: 10.1016/j.materresbull.2007. 04.025

Conflict of Interest: The authors declare that the research was conducted in the absence of any commercial or financial relationships that could be construed as a potential conflict of interest.

Copyright $\odot 2020 \mathrm{Ju}$, Wang, Huang, Zhang, Jin, Sun, Li and Chen. This is an open-access article distributed under the terms of the Creative Commons Attribution License (CC BY). The use, distribution or reproduction in other forums is permitted, provided the original author(s) and the copyright owner(s) are credited and that the original publication in this journal is cited, in accordance with accepted academic practice. No use, distribution or reproduction is permitted which does not comply with these terms. 